\title{
Mixed duopoly, privatization and the shadow cost of public funds
}

C. Capuano and G. De Feo

Discussion Paper 2008-15

Département des Sciences Économiques

de l'Université catholique de Louvain 


\title{
CORE DISCUSSION PAPER
}

$2008 / 19$

\section{Mixed duopoly, privatization and the shadow cost of public funds \\ Carlo CAPUANO ${ }^{1}$ and Giuseppe DE FEO ${ }^{2}$}

\author{
March 2008
}

\begin{abstract}
The purpose of this paper is to investigate the effect of privatization in a mixed duopoly, where a private firm competes in quantities with a welfare-maximizing public firm. We consider two inefficiencies of the public sector: a possible cost inefficiency, and an allocative inefficiency due to the distortionary effect of taxation (shadow cost of public funds). Furthermore, we analyze the effect of privatization on the timing of competition by endogenizing the determination of simultaneous (Nash-Cournot) versus sequential (Stackelberg) games using the model developed by Hamilton and Slutsky (1990). The latter is especially relevant for the analysis of privatization, given that results and policy prescription emerged in the literature crucially rely on the type of competition assumed. We show that privatization has generally the effect of shifting from Stackelberg to Cournot equilibrium and that, absent efficiency gains privatization never increases welfare. Moreover, even when large efficiency gains are realized, an inefficient public firm may be preferred.
\end{abstract}

Keywords: mixed oligopoly, privatization, endogenous timing, distortionary taxes.

JEL Classification: H2, H42, L13, L32, L33

\footnotetext{
${ }^{1}$ Department of Economics, University of Naples Federico II, Italy. E-mail: carlo.capuano@unina.it ${ }^{2}$ CORE, Université catholique de Louvain, Belgium; Department of Economics, University of Salerno, Italy and Department of Economics, University of Strathclyde, U.K. E-mail: Giuseppe.defeo@ strath.ac.uk

We wish to thank Jean Hindriks, Rabah Amir, Paul Belleflamme, Vincent Vannetelbosch, Pierre Pestieau, Francesca Stroffolini, Antonio Acconcia, Alfredo Del Monte, Oscar Amerighi, Massimo Salzano, Alessandro Petretto, Giacomo Calzolari, Vincenzo Denicolo and Toshihiro Matsumura. This work also benefited from comments from seminar audiences at Universities of Bologna, Verona, Pavia, Tokyo and Lisboa. The second author gratefully acknowledges financial support from Department of Economics, University of Salerno.

This paper presents research results of the Belgian Program on Interuniversity Poles of Attraction initiated by the Belgian State, Prime Minister's Office, Science Policy Programming. The scientific responsibility is assumed by the authors.
} 



\section{Introduction}

In the last decades of the XX century a process of liberalization and/or privatization occurred in most of the industrialized countries and, since then, public utilities are generally no longer provided by public monopolies. The motivations for this program were essentially linked to the general perception of poor performance of public monopolies and to the idea that entry of private subjects could enhance efficiency. For example, during the nineties, in Italy, in France and in UK, as in many EU countries, the public incumbent faced the entry of private competitors in many communication services. The same occurred in the production of electricity, in gas retailing and more recently in some postal services. In the same years, national (public) airlines started competing with private or foreign ones in the domestic markets. Moreover, examples of public monopolies that became mixed oligopoly can be found in a broad range of industries including railways, steel and overnight-delivery industries, as well as services including banking, home loans, health care, life insurance, hospitals, broadcasting, and education. ${ }^{1}$ In these cases, instead of regulating a privatized monopoly, governments decided to enforce a facility-based competitions in order to achieve a so-called dynamic efficiency. ${ }^{2}$

Our analysis starts downward the liberalization process of a public monopoly, and the aim of the present work is to evaluate the effects of the following privatization. Since we mainly refer to public utility markets open to competition, we consider a mixed duopoly in which firms are characterized by increasing returns to scale (with fixed and constant marginal costs) and we assume that the public firm is typically less efficient than its private competitor. ${ }^{3}$

The first novel contribution of this paper is represented by the introduction of the shadow cost of public funds in the public firm's objective function. That is, we assume that the public firm is required to take into account the distortionary effect of the taxes that are needed to cover its deficit and, in general, public expenditures. In fact, absent lump-sum tax instruments, if government rises 1 Euro from taxation, society pays $(1+\lambda)$ Euros. Coherently, public profits, when positive, avoid an equivalent public transfer, reducing distortionary taxes. ${ }^{4}$ As initially analyzed in Meade (1944) and exploited in Laffont and Tirole (1986, 1993), this approach has been used to characterize public monopolies running a deficit and, more generally, regulated markets. Here we apply the same analysis to a public firm competing in a duopoly and to the effects of privatization, given that getting money for reducing public debt or distortionary taxes, is often a complementary target of privatization. The main consequence is that, taking into account the shadow cost of public funds, the public firm puts more weight

\footnotetext{
${ }^{1}$ In industrial organization the term mixed oligopolies has been used to describe imperfectly competitive markets in which public firms compete with private ones.

${ }^{2}$ For deeper viewpoints on the role played by facility-based competition in EU and US Telecommunications liberalization and regulation processes see Taschdjian (1997) and Stehmann and Borthwick (1994).

${ }^{3}$ Differently from Cremer et al. (1989), the public firm's higher cost is not a neutral transfer from firm to workers belonging to the same economy but, as an $X$-inefficiency, it reduces any utilitarian measure of welfare.

${ }^{4}$ Since public firm's profit or deficit are not a neutral transfer among agents of the same economy, they ought not to be weighted as private firm's profits or consumer net surplus in the utilitarian measure of welfare, but they should be weighted $(1+\lambda)$.
} 
on its own profits mimicking, at least partially, the behavior of a private firm.

The second contribution of this work is that we consider the effect of privatization on the timing of competition by endogenizing the determination of simultaneous (Nash-Cournot) versus sequential (Stackelberg) games. That is, the structure of the game is not assumed $a$ priori, but is the result of preplay independent and simultaneous decisions by the players. In fact, in many economic situations it is often more reasonable to assume that firms choose not only what action to take, but also when to take it. Moreover, we believe that this approach is especially relevant for the analysis of privatization, given that results and policy prescriptions emerged in the literature crucially rely on the type of competition assumed. For example, in de Fraja and Delbono (1989) it is shown that privatization may improve welfare under Cournot competition even without efficiency gains; while, if a Stackelberg game with public leadership is exogenously assumed, this cannot occur. ${ }^{5}$ In another paper, Beato and Mas-Colell (1984) show that welfare may be higher when the public firm is the follower than when it is the leader in a Stackelberg game. In this way they provided an argument against the standard view of the so-called Second-Best literature (see, for example, Rees, 1984; Bös, 1986) that claimed the sub-optimality of the marginal-cost pricing rule. ${ }^{6}$

In the present work, in order to endogenize the timing of the game, we apply the model developed by Hamilton and Slutsky (1990) to the mixed oligopoly framework. In their insightful paper, the authors build an endogenous timing game by adding to the basic quantity game a preplay stage at which players simultaneously and independently decide whether to move early or late in the basic game. Therefore, the type of competition endogenously emerges in the subgame-perfect equilibrium (SPE) of this extended game. Amir and Grilo (1999) apply this model to a private duopoly showing that, in a quantity setting with strategic substitutability, Cournot equilibria always result as the SPE of the endogenous timing game. Pal (1998) addresses the issue of endogenous order of moves in a mixed oligopoly by adopting the same game structure. It is shown that sequential playing always emerges as the endogenous timing and both Stackelberg solutions are the SPE of the mixed-duopoly game. Even though after Pal (1998) other authors analyzed the endogenous timing in mixed oligopolies, there is no work, at our best knowledge, that extends this line of research to the welfare evaluation of privatization. $^{7}$

The main results of our analysis can be summed up as follows.

With respect to the determination of the endogenous timing in mixed oligopoly, our results differ from Pal (1998), since in our model setting either Nash, or private leadership or both Stackelberg outcomes can result as subgame-perfect equilibria (SPE) of the endogenous timing game. Moreover, following the intuition of Beato and Mas-Colell (1984), we show that when

\footnotetext{
${ }^{5}$ The assumption of decreasing returns to scale is fundamental to their result that privatization may increases welfare. This is generally not the case of a public utility provider.

${ }^{6}$ See de Fraja and Delbono (1990) for a survey of these models.

${ }^{7}$ Matsumura (2003), Cornes and Sepahvand (2003) and Sepahvand (2004) apply the same model to international mixed oligopolies finding that public leadership may emerge as the unique SPE of the endogenous timing game.
} 
both Stackelberg game are SPE of the endogenous timing game, private leadership is preferred by the public firm and it is indeed selected when risk-dominance is used as the equilibrium selection criterion.

With respect to the evaluation of the welfare impact of privatization, differently from de Fraja and Delbono (1989), we find that, absent efficiency gains, privatization never increases welfare and that, even when large efficiency gains are realized by privatization, an inefficient public firm may be preferred. The last result relies on the fact that only with a public firm sequential outcomes (that are always welfare superior) may be supported as SPE of the endogenous timing game. Conversely, with private-owned firms, simultaneous equilibria are always implemented.

It is worth noting that our results are obtained in a context of complete information, and under the assumption that government has the full bargaining power in the privatization process; that is, the price paid by the new private owners for the former public firm is assumed to be equal to its profit in the new (Cournot) equilibrium. This assumption drives the results in favor of privatization, since it overweights the revenue from privatization by $\lambda$ in any welfare comparison.

In what follows, the next Section sets up the model. Section 3 is focused on the issue of endogenous timing in mixed oligopoly, while Section 4 is devoted to the analysis of privatization. Our conclusions are delegated to Section 5. All the proofs are collected in the Appendix.

\section{The basic setting}

In a static, partial equilibrium analysis, we consider the simplest setting of a mixed duopoly, where a private and a public firm, respectively labeled with $i=p, g$, produce a commodity and compete in a quantity game. Demand preferences are described by a linear function where intercept and slope are normalized to one:

$$
p\left(q_{g}, q_{p}\right)=1-q_{p}-q_{g}
$$

Both firms are characterized by constant marginal costs, $c_{i} \geq 0$, and fixed costs, $K_{i} \geq 0$, corresponding to irreversible investments. ${ }^{8}$ We assume that the public firm is already in the market and its fixed cost is sunk. Conversely, the private firm's fixed cost is borne only in case of producing. Moreover, the private firm's marginal cost is normalized to zero, $c_{p}=0$, while the public firm's one is positive, $c_{g}=c \geq 0$. That means, $c$ is an index of the public firm's inefficiency.

The private firm maximizes its profit:

$$
\Pi_{p}\left(q_{g}, q_{p}\right)=\left(1-q_{g}-q_{p}\right) q_{p}-K_{p}
$$

\footnotetext{
${ }^{8}$ We consider that the assumption of increasing returns to scale is coherent with the presence of a public incumbent, former monopolist, in a liberalized public utility industry. Nevertheless, the assumption decreasing return to scale is popular in the literature. For papers adopting constant marginal costs, see Cremer et al. (1989) and Martin (2004); while for papers adopting increasing marginal costs, see Beato and Mas-Colell (1984), de Fraja and Delbono (1989), Fjell and Pal (1996), Pal and White (1998), Matsumura (1998).
} 
The public firm maximize an utilitarian measure of welfare taking into account the shadow cost of public funds, $\lambda>0$. This parameter is a measure of the dead-weight loss due to distortionary taxation. In particular, let $S(Q)$ denote the consumer gross surplus, where $Q=q_{p}+q_{g}$ is the industry total output. We assume that government can choose the public firm's output level $q_{g}$ and it can make a monetary transfer $T$ to the public firm. Then, in the presence of the shadow cost of public funds, the maximization problem of the government is:

$$
\begin{aligned}
& \max _{q_{g}, T} W\left(q_{p}, q_{g}\right)=S\left(q_{p}+q_{g}\right)-C_{g}\left(q_{g}\right)-C_{p}\left(q_{p}\right)-\lambda T \\
& \text { such that } \widetilde{\Pi}_{g}=p\left(q_{p}+q_{g}\right) q_{g}-C_{g}\left(q_{g}\right)-K_{g}+T \geq 0
\end{aligned}
$$

where $\widetilde{\Pi}_{g}$ is the public firm's budget including the (positive or negative) transfer $T$. Notice that the (participation) constraint (1) is not a hard budget balance constraint but it is compatible with operative losses when $T$ is positive. From (1) we get

$$
T=\widetilde{\Pi}_{g}-\left[p(Q) q_{g}-C_{g}\left(q_{g}\right)-K_{g}\right]
$$

and substituting $T$ in the objective function we obtain:

$$
\begin{aligned}
\max _{q_{g}} \quad W= & S\left(q_{p}+q_{g}\right)-C_{g}\left(q_{g}\right)-C_{p}\left(q_{p}\right)-\lambda\left[\widetilde{\Pi}_{g}-\left(p(Q) q_{g}-C_{g}\left(q_{g}\right)-K_{g}\right)\right] \\
= & S\left(q_{p}+q_{g}\right)-C_{g}\left(q_{g}\right)-C_{p}\left(q_{p}\right)+\lambda\left(p(Q) q_{g}-C_{g}\left(q_{g}\right)-K_{g}\right)-\lambda \widetilde{\Pi}_{g} \\
& \text { such that } \quad \widetilde{\Pi}_{g} \geq 0
\end{aligned}
$$

Since welfare is decreasing in $\widetilde{\Pi}_{g}$ when $\lambda$ is positive, it is optimal to set $\widetilde{\Pi}_{g}=0$. Then, we have:

$$
T=-\left[p(Q) q_{g}-C_{g}\left(q_{g}\right)-K_{g}\right]
$$

The problem can be rewritten unconstrained as follows:

$$
\max _{q_{g}} W=S\left(q_{p}+q_{g}\right)-C_{g}\left(q_{g}\right)-C_{p}\left(q_{p}\right)+\lambda\left(p(Q) q_{g}-C_{g}\left(q_{g}\right)-K_{g}\right)
$$

Defining the consumer net surplus as

$$
C S(Q)=S(Q)-p(Q)\left(q_{p}+q_{g}\right)
$$

and the public firm's operative profit as

$$
\Pi_{g}\left(q_{g}, q_{p}\right)=p(Q) q_{g}-C_{g}\left(q_{g}\right)-K_{g}
$$

the maximization problem of the government is reduced to:

$$
\max _{q_{g}} W\left(q_{g}, q_{p}\right)=C S(Q)+\Pi_{p}\left(q_{g}, q_{p}\right)+(1+\lambda) \Pi_{g}\left(q_{g}, q_{p}\right)
$$

So, the objective defined in equation (4) implies that a transfer occurs in order to guarantee the public firm's budget balance. This transfer is positive (negative) when the public firm's profits are negative (positive). 
The objective function (4) can be also interpreted as a weighted average of welfare, defined as the net surplus generated in the market, and the public firm's profit, where the former is weighted by $1 /(1+\lambda)$, the latter by $\lambda /(1+\lambda)$.

$$
\begin{array}{r}
W\left(q_{g}, q_{p}\right)=V\left(q_{g}, q_{p}\right)+\lambda \Pi_{g}\left(q_{g}, q_{p}\right) \\
P \frac{1}{1+\lambda} V\left(q_{g}, q_{p}\right)+\frac{\lambda}{1+\lambda} \Pi_{g}\left(q_{g}, q_{p}\right)
\end{array}
$$

We know that other works on mixed oligopoly consider a weighted average of welfare as public firm's objective function. In fact, if we had assumed a hard budget balance constraint without a public transfer, as in Cremer et al. (1989), the weight given to the public firm's profit would have been endogenous and equal to the associate Lagrangian multiplier. Alternatively, as in Hindriks and Claude (2006) the weight could be positively related to the endogenous share of a partially privatized firm owned by private investors, while as in Matsumura (1998), due to incentive problem between government and public management, in equilibrium a negative relation may occur. In the present paper the weight of the public firm's profit is exogenously correlated to the shadow costs of public funds. In our analysis, introducing $\lambda$ extends the contract theory approach of public monopoly regulation to the case of (mixed) oligopoly.

The best-reply (or reaction) function of the private firm is derived, as usual, from the first order condition:

$$
\frac{\partial \Pi_{p}\left(q_{g}, q_{p}\right)}{\partial q_{p}}=p\left(q_{g}, q_{p}\right)+p^{\prime}\left(q_{g}, q_{p}\right) q_{p}=0
$$

In the presence of fixed costs, the private firm's reaction function ought to be truncated in the point it crosses the zero-isoprofit curve and on-the-boundary solutions can occur in equilibrium. Given the model setting, it can be written explicitly in the following way:

$$
\begin{aligned}
r_{p}\left(q_{g}\right) & =\left\{\begin{array}{cll}
\frac{1}{2}\left(1-q_{g}\right) & \text { if } & q_{g}<\overline{q_{g}} \\
0 & \text { if } & q_{g} \geq \overline{q_{g}}
\end{array}\right. \\
\text { where } \overline{q_{g}} & =q_{g}: \Pi_{p}\left(r_{p}\left(q_{g}\right), q_{g}\right)=0
\end{aligned}
$$

The public firm's first order condition can be derived from the objective (5):

$$
\begin{aligned}
\frac{\partial W\left(q_{g}, q_{p}\right)}{\partial q_{g}} & =\frac{\partial V\left(q_{g}, q_{p}\right)}{\partial q_{g}}+\lambda \frac{\partial \Pi_{g}\left(q_{g}, q_{p}\right)}{\partial q_{g}} \\
& =\left[p\left(q_{g}, q_{p}\right)-c\right]+\lambda\left[p\left(q_{g}, q_{p}\right)-c+p^{\prime}\left(q_{g}, q_{p}\right) q_{g}\right]=0
\end{aligned}
$$

Notice that when $\lambda=0$ public firm's output decision follows the marginal cost pricing rule, and the first term in square brackets measure its effect on total surplus (allocative effect). The second term is the effect on the public firm's profits, since the latter prevents the government from using distortionary taxation to raise money (we call it the distortionary effect). When $\lambda \rightarrow+\infty$, the public firm plays as a private (Cournot) competitor. 
Since there is no hard budget balance constraint and its fixed cost $K_{g}$ is sunk, the public firm's reaction function is not truncated and it can be explicitly derived:

$$
r_{g}\left(q_{p}\right)=\max \left\{\frac{1+\lambda}{1+2 \lambda}\left(1-c-q_{p}\right) ; 0\right\}
$$

However, we want to focus on the case in which both firms produce strictly positive quantities when they play simultaneously; so, we provide some assumptions on the admissible set in the parameters space.

Assumption 1 The parameters $c$ and $\lambda$ belong to the subspace

$$
A \subset \mathbb{R} \times \mathbb{R}=\left\{(c, \lambda) \mid c \in\left(0, \frac{1}{2}\right) \vee \lambda \in[0, \lambda]\right\}
$$

where $\bar{\lambda}$ is a finite, reasonable value of the shadow cost of public funds.

Assumption 2 The private firm's fixed cost $K_{p}$ belongs to the subspace $B \subset \mathbb{R}=\left[0, \bar{K}_{p}\right]$, where $\bar{K}_{p}$ is smaller than the producer surplus of the private firm in any (simultaneous or sequential) equilibrium.

In Figure 1, the reaction functions are depicted. Coherently with the Assumptions 1 and 2 , the intersection occurs in the interior of the parameters space where both firms produce strictly positive quantities.

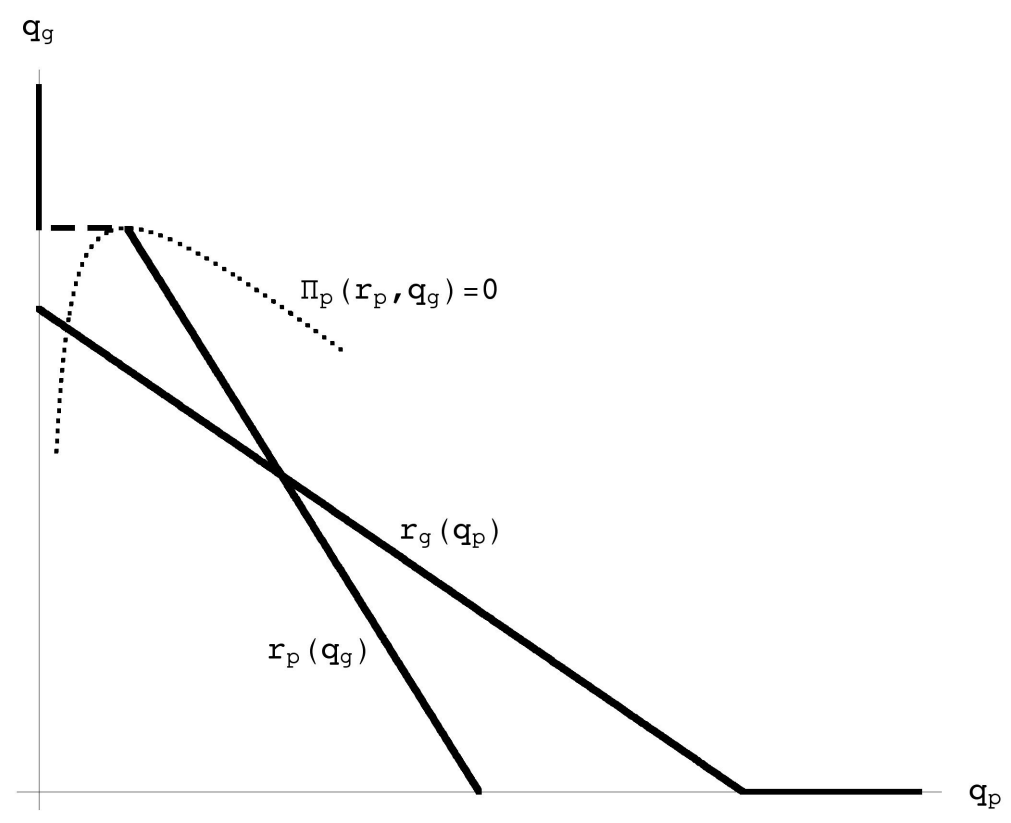

Figure 1: Firms' reaction functions

An increase in $\lambda$ has the effect of reducing both intercept and slope of the public firm's best-reply. When $\lambda$ tends to infinite, the public firm plays as a profit maximizer. 


\section{Endogenous timing in a mixed duopoly}

In this Section we investigate how the determination of simultaneous (Nash-Cournot) versus sequential (Stackelberg) games is the result of preplay independent and simultaneous decisions by the players. ${ }^{9}$

In many mixed oligopoly and privatization works, the timing of the competition (simultaneous or sequential) is generally assumed, and simultaneous playing is mostly adopted. ${ }^{10}$ Of course, this assumption is not neutral and it affects the results and the policy prescriptions on privatization. For example, without efficiency gains, in de Fraja and Delbono (1989) it is shown that privatization never improves welfare when a Stackelberg game with public leadership is played; on the contrary, privatization may be welfare improving in the simultaneous setting. Then, the welfare impact of privatization crucially depends on the assumed timing.

More recently, other works introduced the idea that the order of play should result from the players' timing decision. In particular, in a private duopoly with strategic substitutability it has been proved by Hamilton and Slutsky (1990) and by Amir and Grilo (1999) that simultaneous play emerges as the unique equilibrium of the endogenous game. Conversely, in a mixed duopoly Pal (1998) shows that sequential play always occurs in equilibrium.

Coherently with this approach, in order to endogenize the timing of the play, we use the game with observable delay defined by Hamilton and Slutsky (1990). In the first stage firms simultaneously and independently choose the timing of action (whether to move early or late) and then, once observing each other decision, they play the basic quantity game. The extensive form of the game is represented in Figure 2.

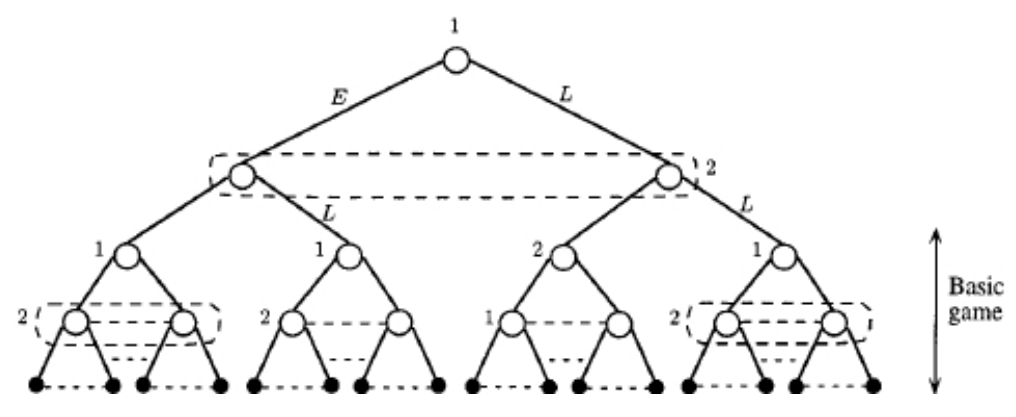

Figure 2: The extensive form of the game with observable delay (Hamilton and Slutsky, 1990)

The relevant equilibrium concept is the subgame-perfect equilibrium (SPE) and each player decides the timing of action according to the outcomes in the second stage (the basic game). Of course, none of the firms can choose the type of competition by itself, but it can only

\footnotetext{
${ }^{9}$ Notice that in formal game-theoretical terms, Stackelberg's proposal is not to be understood as a new solution concept for one-shot games, but rather as a subgame-perfect equilibrium of a two-stage game of perfect information with exogenously given first and second movers.

${ }^{10}$ In Cremer et al. (1989, p. 284), the reason for using a simultaneous timing is summarized as follows: "The common use of the Nash equilibrium in industrial organization [...] suggests that this is at least as plausible as the leader-follower situations [...]."
} 
eliminate some outcome. For example, if firm $i$ decides to move early two outcomes are possible according to the decision of the other player; only the Stackelberg outcome where firm $i$ is follower is ruled out by its decision.

Assuming existence and uniqueness of equilibria in each basic game, the following Proposition summarizes the results obtained in Hamilton and Slutsky (1990) for any two-player game.

Proposition 3 Consider a two-player game for which the Nash and the two Stackelberg equilibria exist. Given that both players always prefer to be a Stackelberg leader than a simultaneous player, the set of (pure strategy) SPE of the endogenous timing game is defined in the following way:

i) if the Stackelberg follower payoff is lower than the Nash payoff for each firm, then the unique SPE of the endogenous timing game is the Nash equilibrium where both firms decide to move early;

ii) if the Stackelberg follower payoff is strictly larger than the Nash payoff for each firm, then the both Stackelberg equilibria are SPE of the endogenous timing game;

iii) if firm i's Stackelberg follower payoff is strictly larger than its Nash payoff and if firm $j$ prefers to play simultaneously than to be Stackelberg follower, then the unique SPE of the endogenous timing game is the Stackelberg equilibrium with firm $j$ being the leader.

Proof. The proof of this Proposition follows from Theorems II, III and IV in Hamilton and Slutsky (1990).

The intuition behind these results is the following. Given that both firms prefer to be leader than to play simultaneously, if the Nash payoff is higher than the follower payoff, then any firm has a dominant strategy to move early. But if one firm prefers its follower payoff to the Nash payoff, there is no dominant strategy: when the other player moves early it prefers to move late and vice versa. This explains the three possible outcomes listed in Proposition 3 .

We use Proposition 3 in order to determine the endogenous timing equilibrium, where the existence and the uniqueness of the equilibria in each basic game are assured by Assumptions 1 and 2. The reduced form of the endogenous timing game for the mixed duopoly is represented in Table 1.

\begin{tabular}{|c|c|c|}
\cline { 2 - 3 } \multicolumn{1}{c|}{} & \multicolumn{2}{c|}{ Private Firm } \\
\hline Public Firm & Early & Late \\
\hline Early & $W^{M N}(),. \Pi_{p}^{M N}()$. & $W^{G L}(),. \Pi_{p}^{G L}()$. \\
\hline Late & $W^{P L}(),. \Pi_{p}^{P L}()$. & $W^{M N}(),. \Pi_{p}^{M N}()$. \\
\hline
\end{tabular}

Table 1: The reduced form of the endogenous timing game. MN, PL and GL stay respectively for Nash, Private Leadership and Public Leadership equilibria. 
In order to solve the game we need to compare the equilibrium payoffs in each basic game. In what follows the simultaneous and sequential equilibria are derived.

\subsection{Simultaneous equilibrium}

When firms play simultaneously, the equilibrium output levels solve the system of the bestreply functions (6) and (7). We refer to this equilibrium as a mixed duopoly Nash equilibrium and the equilibrium values are labeled by $M N$. The output levels and the price in equilibrium are

$$
\begin{aligned}
q_{g}^{M N} & =(1+\lambda) \frac{(1-2 c)}{(3 \lambda+1)} ; \quad q_{p}^{M N}=c+\lambda \frac{(1-2 c)}{(3 \lambda+1)} \\
Q^{M N} & =(1-c)-\lambda \frac{(1-2 c)}{(3 \lambda+1)} ; \quad p^{M N}=c+\lambda \frac{(1-2 c)}{(3 \lambda+1)}
\end{aligned}
$$

Notice that when $\lambda=0$, the public firm's equilibrium output is such that the market price is always equal to its marginal cost. It means that the public firm implements a total output level equal to the one derived in the case of a welfare maximizer (but inefficient) monopoly; but now the welfare is higher. ${ }^{11}$ Moreover, when the public firm is as efficient as the private one, the first best solution is implemented.

As $\lambda$ increases, the public firm equilibrium output $q_{g}^{M N}$ decreases and $q_{p}^{M N}$ increases; then, the industry total cost decreases enhancing productive efficiency. This is because the public firm's concern for public transfers serves as a credible commitment to decrease its output. Moreover, since the best-reply functions are contractions, the total output level, $Q^{M N}$, decreases and the market price $p^{M N}$ increases. It is obvious that the effect on consumer surplus is negative, raising an allocative inefficiency. ${ }^{12}$ The private firm's profit and welfare represent the payoffs of the players and in the simultaneous case are:

$$
\begin{aligned}
\Pi_{p}^{M N} & =\left(\frac{c+\lambda(1+c)}{3 \lambda+1}\right)^{2}-K_{p} \\
W^{M N} & =\frac{1-2 c(1+\lambda)(1+2 \lambda)^{2}+c^{2}(1+\lambda)^{2}(3+8 \lambda)+2 \lambda(3+\lambda(5+\lambda))}{2(3 \lambda+1)^{2}}-(1+\lambda) K_{g}-K_{p}
\end{aligned}
$$

\subsection{Sequential equilibria}

A Stackelberg equilibrium of this game corresponds to the SPE of a two stage game of perfect information in which the second mover (follower) chooses an action after having observed the action of the first mover (leader). Then, the Stackelberg equilibrium imposes that: (i) the strategy of the second mover is a selection from its reaction function; and (ii) the first mover chooses an action that maximizes its objective given the anticipation of the rival's reaction.

In what follows we first analyze the case of public leadership and then the private leadership equilibrium.

\footnotetext{
${ }^{11}$ This is because the same total output is partially produced by the more efficient private competitor.

${ }^{12}$ There exists a clear trade off between technical and allocative efficiency, and the net effect on total surplus is ambiguous and depends on the parameters.
} 


\begin{tabular}{|l|c|c|c|}
\cline { 2 - 4 } \multicolumn{1}{c|}{} & $q_{p}^{G L}$ & $q_{g}^{G L}$ & $\Pi_{p}^{G L}$ \\
\hline$c<\frac{1+2 \lambda}{4(1+\lambda)}$ & $\frac{2 c(1+\lambda)+\lambda}{(1+4 \lambda)}$ & $\frac{(1+2 \lambda)-4 c(1+\lambda)}{(1+4 \lambda)}$ & $\frac{(2 c(1+\lambda)+\lambda)^{2}}{(1+4 \lambda)^{2}}-K_{p}$ \\
\hline$c \geq \frac{1+2 \lambda}{4(1+\lambda)}$ & $\frac{1}{2}$ & 0 & $\frac{1}{4}-K_{p}$ \\
\hline \hline & \multicolumn{3}{|c|}{$W^{G L}$} \\
\hline$c<\frac{1+2 \lambda}{4(1+\lambda)}$ & $\frac{1}{2} \frac{\left(4 \lambda-2 c-6 c \lambda+4 c^{2}+\lambda^{2}-4 c \lambda^{2}+8 c^{2} \lambda+4 c^{2} \lambda^{2}+1\right)}{(1+4 \lambda)}-(1+\lambda) K_{g}-K_{p}$ \\
\hline$c \geq \frac{1+2 \lambda}{4(1+\lambda)}$ & \multicolumn{3}{|c|}{$\frac{3}{8}-(1+\lambda) K_{g}-K_{p}$} \\
\hline
\end{tabular}

Table 2: The public leadership (GL) equilibrium quantities, profits and welfare.

Public leadership (GL).

When the public firm moves before its private competitor, the equilibrium quantities solve the following equation system:

$$
\begin{aligned}
q_{g}^{G L} & =\arg \max W\left(q_{g}, r_{p}\left(q_{g}\right)\right) \\
q_{p}^{G L} & =r_{p}\left(q_{g}^{G L}\right)
\end{aligned}
$$

The solution is:

$$
\begin{aligned}
q_{g}^{G L} & =\max \left\{\frac{(1+2 \lambda)-4 c(1+\lambda)}{(1+4 \lambda)}, 0\right\} \\
q_{p}^{G L} & =\frac{1}{2}\left(1-q_{g}^{G L}\right)
\end{aligned}
$$

We have to distinguish two cases since there exists a threshold value of the marginal cost of the public firm such that $\forall c \in\left(0, \frac{1+2 \lambda}{4(1+\lambda)}\right)$ the public firm produces a positive quantity in equilibrium. When $c \in\left[\frac{1+2 \lambda}{4(1+\lambda)}, \frac{1}{2}\right)$, the public firm prefers not to produce and the private firm acts as a monopolist: its quantity, market price, and welfare are the same as in a private monopoly.

Since the threshold value $\frac{1+2 \lambda}{4(1+\lambda)}$ is increasing, as $\lambda$ increases an higher level of inefficiency is compatible with positive production by the public firm. In Table 2 quantities, profits and welfare in the public leadership equilibrium are summarized.

Private leadership $(P L)$.

Assume that the private firm moves before its public competitor, that is, it behaves as a leader in the Stackelberg game. The equilibrium quantities solve the following equation system:

$$
\begin{aligned}
q_{p}^{P L} & =\arg \max \Pi_{p}\left(r_{g}\left(q_{p}\right), q_{p}\right) \\
q_{g}^{P L} & =r_{g}\left(q_{p}^{P L}\right)
\end{aligned}
$$




\begin{tabular}{|l|c|c|c|}
\cline { 2 - 4 } \multicolumn{1}{c|}{} & $q_{p}^{P L}$ & $q_{g}^{P L}$ & $\Pi_{p}^{P L}$ \\
\hline$c<\frac{\lambda}{3 \lambda+1}$ & $\frac{1}{2} \frac{(c+\lambda+c \lambda)}{\lambda}$ & $\frac{(\lambda-c-3 c \lambda)(1+\lambda)}{2 \lambda(1+2 \lambda)}$ & $\frac{1}{4} \frac{(c+\lambda+c \lambda)^{2}}{\lambda(2 \lambda+1)}-K_{p}$ \\
\hline$c \geq \frac{\lambda}{3 \lambda+1}$ & $1-c$ & 0 & $c(1-c)-K_{p}$ \\
\hline \hline & \multicolumn{3}{|c|}{$W^{P L}$} \\
\hline$c<\frac{\lambda}{3 \lambda+1}$ & \multicolumn{3}{|c|}{$\frac{\left(4 \lambda-4 c \lambda+4 c^{2}+8 \lambda^{2}+\lambda^{3}-10 c \lambda^{2}+17 c^{2} \lambda-6 c \lambda^{3}+22 c^{2} \lambda^{2}+9 c^{2} \lambda^{3}\right)}{8(2 \lambda+1) \lambda}-(1+\lambda) K_{g}-K_{p}$} \\
\hline$c \geq \frac{\lambda}{3 \lambda+1}$ & \multicolumn{3}{c}{$\frac{1}{2}-\frac{1}{2} c^{2}-(1+\lambda) K_{g}-K_{p}$} \\
\hline
\end{tabular}

Table 3: The private leadership (PL) equilibrium values of quantities, profits and welfare.

The solution is:

$$
\begin{aligned}
q_{p}^{P L} & =\min \left\{\frac{1}{2} \frac{(c+\lambda+c \lambda)}{\lambda}, 1-c\right\} \\
q_{g}^{P L} & =\frac{1+\lambda}{1+2 \lambda}\left(1-c-q_{p}^{P L}\right)
\end{aligned}
$$

As before, we have two different cases depending on the value of $c . \forall c \in\left(0, \frac{\lambda}{3 \lambda+1}\right)$ the public firm produces a positive quantity in equilibrium; more precisely, it is optimal for the private leader to choose a quantity such that the public firm's best response is positive. When $c \in\left[\frac{\lambda}{3 \lambda+1}, \frac{1}{2}\right)$ the public firm does not produce in equilibrium and the private firm plays as a public (inefficient) monopolist: its quantity, as a limit level, is such that the market price is equal to the marginal cost of the public firm. ${ }^{13}$ Of course total surplus is higher because the private competitor produces more efficiently.

Moreover, as $\lambda$ increases, a larger inefficiency is compatible with a positive production by the public firm. In Table 3 quantities, profits and welfare in the private leadership equilibrium are summarized.

\subsection{Endogenous timing equilibria}

In this section we derive the endogenous timing equilibria of the mixed duopoly game. In order to apply Proposition 3 we need to rank the private and public firms' payoff in the different equilibria. In particular, in Lemma 4 we compare the private firm's profit under public leadership (i.e., the follower payoff) and in the Nash equilibrium, while in Lemma 5 we compare welfare under private leadership (again the follower payoff) with the one in the Nash equilibrium. It is worth noting that these comparisons are sufficient to apply Proposition 3. In fact, any player always prefers to be leader than to play simultaneously, by the nature of Stackelberg equilibria. Moreover, the comparison between the leader and the follower payoff is useless since no firm can unilaterally switch from one sequential equilibrium to the other.

\footnotetext{
${ }^{13}$ This is the standard case when $\lambda=0$ : the public follower can always produce the quantity needed to achieve this target and, anticipating this strategy, the best action for the private firm is to produce that quantity.
} 
Lemma 4 There exists a subspace $F_{1}=(c, \lambda) \subseteq A$, such that the private firm strictly prefers the public leadership equilibrium to the mixed duopoly Nash equilibrium. In the subspace $\widehat{F}_{1}=$ $A-F_{1}$ the reverse is true.

This result totally relies on the choice of the public leader to produce more or less than in the simultaneous equilibrium; and this choice depends on the public firm's objective being increasing or decreasing in the rival's output in the Nash equilibrium point.

In fact, private firm's profit is strictly decreasing in the public firm's output in any interior point ${ }^{14}$, and so, if $q_{g}^{P L}<q_{g}^{M N}$, the private firm prefers to be follower than to play simultaneously.

The public leader chooses to produce a smaller quantity with respect to the Nash equilibrium if $\frac{\partial W\left(q_{g}, q_{p}\right)}{\partial q_{p}}>0$ in the Nash equilibrium. In fact, if its objective is increasing in the quantity produced by the rival, the public leader prefers to reduce its quantity anticipating that the private firm will increase the output, enhancing in this way the welfare. ${ }^{15}$

$$
\frac{\partial W\left(q_{g}, q_{p}\right)}{\partial q_{p}}=\frac{\partial V}{\partial q_{p}}+\lambda \frac{\partial \Pi_{g}}{\partial q_{p}}=p\left(q_{g}, q_{p}\right)+\lambda p^{\prime}\left(q_{g}, q_{p}\right) q_{g}=p\left(q_{g}, q_{p}\right)-\lambda q_{g}
$$

In the Nash equilibrium:

$$
\begin{aligned}
\left.\frac{\partial W\left(q_{g}, q_{p}\right)}{\partial q_{p}}\right|_{\left(q_{g}^{M N}, q_{p}^{M N}\right)} & =c+\lambda \frac{(1-2 c)}{(3 \lambda+1)}-\lambda(1+\lambda) \frac{(1-2 c)}{(3 \lambda+1)} \\
& =\frac{c\left(2 \lambda^{2}+3 \lambda+1\right)-\lambda^{2}}{(3 \lambda+1)}
\end{aligned}
$$

Then, $\left.\frac{\partial W\left(q_{g}, q_{p}\right)}{\partial q_{p}}\right|_{\left(q_{g}^{M N}, q_{p}^{M N}\right)}>0$ if $c>\frac{\lambda^{2}}{2 \lambda^{2}+3 \lambda+1}$.

This result occurs when the increase in productive efficiency due to the shift of some production to the private firms outweighs the negative allocative efficiency effect due to the reduction in total quantity and the negative distortionary effect due to the reduction in profits.

The threshold $\bar{c}(\lambda)$ is increasing because, as $\lambda$ increases, the distortionary effect makes the public firm more willing to produce a larger quantity. So, only if $c$ is high enough the overall effect of shifting some production to the efficient private competitor is positive.

Lemma 5 There exists a subspace $F_{2}=(c, \lambda) \subseteq A$, such that the public firm strictly prefers the private leadership equilibrium to the mixed duopoly Nash equilibrium. In the subspace $\widehat{F}_{2}=A-F_{2}$ the reverse is true.

As in the previous Lemma, this result has to do with the fact that $W\left(q_{g}, q_{p}\right)$ may be increasing in $q_{p}$. But now what matters is the decision of the private leader, that always increases its output with respect to the Nash equilibrium. As a result, total output increases

\footnotetext{
${ }^{14}$ Indeed, $\partial \Pi_{p}\left(q_{g}, q_{p}\right) / \partial q_{g}=p^{\prime}\left(q_{g}, q_{p}\right) q_{p}<0 \quad \forall q_{p}>0$.

${ }^{15}$ Note that welfare increases despite the total quantity reduction.
} 
and the allocative efficiency effect is positive. Recalling that moving from Nash to the public leadership equilibrium had a negative allocative efficiency effect, we would expect that the parameter space $F_{2}$ is larger $F_{1}$. This intuition is confirmed by the comparison of the thresholds $\underline{c}(\lambda)$ and $\bar{c}(\lambda)$. In fact,

$$
\underline{c}(\lambda)=\frac{3 \lambda^{2}+7 \lambda^{3}}{21 \lambda+34 \lambda^{2}+17 \lambda^{3}+4}<\frac{\lambda^{2}}{2 \lambda^{2}+3 \lambda+1}=\bar{c}(\lambda) \quad \forall \lambda \in(0, \bar{\lambda})
$$

Then, $F_{1} \subset F_{2}$.

In the following Theorem the different SPE of the endogenous timing game are derived.

Theorem 6 Consider a mixed duopoly game in which the order of moves is endogenous. The SPE of the endogenous timing game are defined in the following way:

a) When $(c, \lambda) \in \widehat{F}_{2}$, the mixed duopoly Nash equilibrium is the unique SPE of the endogenous timing game;

b) When $(c, \lambda) \in \widehat{F}_{1} \cap F_{2}$, the unique SPE of the endogenous timing game is the Stackelberg equilibrium with the private firm acting as leader;

c) When $(c, \lambda) \in F_{1}$, both Stackelberg outcomes are the (pure strategy) SPE of the endogenous timing game.

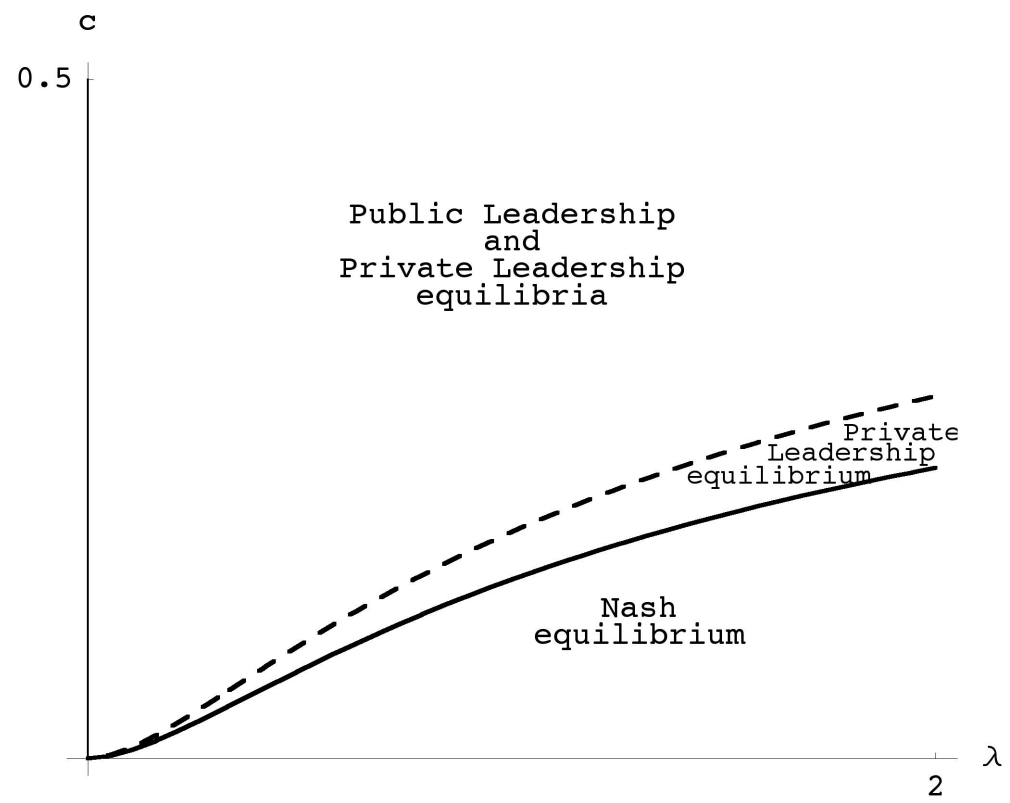

Figure 3: SPE of the endogenous timing game in the space of parameters $(c, \lambda)$

Figure 3 depicts the three possible outcomes of the endogenous timing game in the space $(c, \lambda)$. Without considering $\lambda$, the previous literature (Pal, 1998) defines a unique solution 
where both sequential equilibria are SPE. The novel contribution of our analysis is to enlarge the set of possible outcomes defining conditions under which either private leadership or Nash equilibrium may arise as the unique SPE. The intuition is straightforward. Since the public firm's objective function is a weighted average of total surplus and profits, for low values of $\lambda$ (given $c$ ) our result coincides with Pal's; for high values of $\lambda$ (given $c$ ), the public firm mimics the private firm's behavior and we obtain the same results as Amir and Grilo (1999) in a private duopoly. For intermediate values of $\lambda$, private leadership is the unique SPE since the public firm is more willing to accept a reduction in its own output when total quantity increases (in the PL equilibrium) than when total output decreases (in the GL equilibrium).

Moreover, when we focus on the sequential outcomes, the introduction of $\lambda$ increases the level of inefficiency compatible with a strictly positive quantity produced by the public firm in equilibrium. In particular, in the private leadership case, Pal (1998) shows that the public firm never produces and its presence has a mere strategical role that induces the competitor to produce the limit quantity. In our framework, taking into account the shadow cost of public funds, the public firm usually produces a positive quantity in equilibrium. ${ }^{16}$

\subsection{Equilibrium selection}

In the subspace $F_{1}$ the endogenous timing game of the mixed duopoly has two pure-strategy Nash equilibria. Then, this is a standard coordination game with two pure-strategy Nash equilibria and one mixed-strategy equilibrium. We now analyze the pure-strategy equilibrium selection problem according to the risk dominance criterion developed by Harsanyi and Selten (1988). ${ }^{17}$ Applied to coordination games with two pure-strategy equilibria, this procedure picks the equilibrium that has the largest basin of attraction in the initial beliefs of the players on each other's behavior. In other words, it minimizes the risk of a coordination failure due to the strategic uncertainty that players face in a coordination game (Amir and Stepanova, 2006). This criterion proved to be a powerful selection concept in experimental settings of coordination games (Cooper et al., 1990; Van Huyck et al., 1990) and in evolutionary games characterized by experimentation and myopic learning (Ellison, 1993; Kandori et al., 1993). It is shown that the risk dominant equilibrium is often selected even when it is Pareto dominated by another equilibrium. One equilibrium risk-dominates the other if it is associated with the larger product of deviation losses. In our framework this means that private leadership is selected using the risk-dominance criterion if

$$
\left(W^{P L}-W^{M N}\right)\left(\Pi_{p}^{P L}-\Pi_{p}^{M N}\right)>\left(W^{G L}-W^{M N}\right)\left(W^{G L}-\Pi_{p}^{M N}\right)
$$

Theorem 7 The private leadership equilibrium risk-dominates the public leadership equilib$\operatorname{rium} \forall(c, \lambda) \in F_{1}$.

\footnotetext{
${ }^{16}$ This is true as far as the public firm is not too inefficient. This result enhances the realism of our approach where the public firm represents not only a threat of producing, but it has an active role in the industry.

${ }^{17}$ In the present setting it is possible to show that the standard refinements of Nash equilibrium for normal form games - perfection, properness and strategic stability - cannot be invoked to rule out one of the pure strategy SPE.
} 
Then, the risk dominance criterion selects in the whole set $F_{1}$ the same equilibrium that the Pareto dominance criterion is able to select only in a subspace of $F_{1}$. It is important to highlight that the risk-dominance criterion is applied to the reduced game, and not to the entire two-stage game of endogenous timing, and the two options are a priori entirely different. However, since each subgame has a unique Nash equilibrium and given the use of subgame perfection in this framework, our application of the risk-dominance criterion on the reduced game seems to us rather natural. ${ }^{18}$ Amir and Stepanova (2006) suggest the following interpretation: the private leadership equilibrium is chosen by firms that wish to minimize the risk of coordination failure in their timing decisions.

The preference for the private leadership equilibrium is the main contribution in Beato and Mas-Colell (1984), where it is assumed that the public firm is committed to a decision rule (in their case the marginal-cost pricing rule), and the private firm maximizes its own profit given the decision rule of the public competitor. In the present setting, using the game with observable delay of Hamilton and Slutsky (1990) coupled with risk dominance as a selection criterion, we show that the private leadership equilibrium emerges as the endogenous equilibrium in the mixed duopoly $\forall(c, \lambda) \in F_{2}$.

\section{Welfare effect of privatization}

In this Section we perform a comparative statics exercise in order to analyze the effects of privatization on welfare taking into account the result of the previous Section on the endogenous timing equilibrium.

By privatization we consider the case in which the public firm is sold by the government and the management is instructed by the new owners to maximize profits: ${ }^{19}$

$$
\Pi_{g}\left(q_{g}, q_{p}\right)=\left[p\left(q_{g}, q_{p}\right)-c\right] q_{g}
$$

This change in ownership might have in principle the effect of enhancing the productive efficiency of the former public firm. We consider the two extreme cases in which either no efficiency gain or full efficiency are achieved. In the first case, the privatized firm retains the same technology as before; in the latter, it is able to produce at the same marginal cost of its competitor, here normalized to zero. After privatization, the new reaction function of firm $g$ is:

$$
r_{g}\left(q_{p}\right)=\max \left\{\frac{1}{2}\left(1-c-q_{p}\right), 0\right\}
$$

\footnotetext{
${ }^{18}$ See van Damme and Hurkens (2004) and Amir and Stepanova (2006) for the application of the riskdominance criterion on the reduced game of endogenous timing models in price game duopolies.

${ }^{19}$ As in the mixed duopoly case, we assume that the fixed cost is sunk and already paid by the government. So, it is included in the welfare, weighted $(1+\lambda)$, but not in the privatized firm's profit. Moreover, For simplicity, we keep the same subscripts as in the mixed oligopoly framework. From now on, $g$ stands for the privatized firm.
} 
with $c=0$ in the case of full efficiency gains. Comparing the reaction function before (7) and after privatization, it is easy to see that it becomes steeper. Indeed:

$$
\frac{1+\lambda}{1+2 \lambda}>\frac{1}{2} \quad \forall \lambda \in(0, \bar{\lambda})
$$

and only when $\lambda \rightarrow \infty$ the slope of (7) converges to (6).

Absent efficiency gains, also the intercept is reduced after privatization. With full efficiency gains the intercept increases only when $c>\frac{1}{2(1+\lambda)}$.

The change in the reaction function is not the only effect of privatization. In fact, we have to consider the (possible) change in the endogenous timing equilibrium. In order to derive the SPE of the game after privatization, we can rely on the results in Amir and Grilo (1999) that apply the same endogenous timing structure to a private duopoly. The following Proposition summarizes the result.

Proposition 8 Consider a private duopoly quantity game with strategic substitutes. When the values of the parameters are in the admissible set A, the unique SPE of the endogenous timing game is the Cournot-Nash equilibrium where both firms decide to move early.

Proof of Proposition 8. Under Assumptions 1 and 2 no Nash equilibrium lies on the boundary, i.e. no firm produces zero output. In this case we can apply Theorem 2.2 in Amir and Grilo (1999) that proves that both firms prefer always to be simultaneous player than Stackelberg follower. So, according to point $i$ ) Proposition 3, the unique SPE of the endogenous timing game is the Cournot-Nash equilibrium.

The intuition for this result is clear. Since the firm's profit is strictly decreasing in the rival's output, a private leader always increases its own quantity in comparison with the Cournot-Nash quantity. By the same reason, a private follower is always strictly worse off with respect to the Cournot-Nash equilibrium. Then, sequential play is only sustainable in a mixed duopoly.

The Cournot-Nash equilibrium is the solution of the system of equations (6) and (11). Quantities and price are: ${ }^{20}$

$$
\begin{aligned}
q_{g}^{C N} & =\frac{1-2 c}{3} ; & q_{p}^{C N}=\frac{1+c}{3} \\
Q^{C N} & =\frac{2-c}{3} ; & p^{C N}=\frac{1+c}{3}
\end{aligned}
$$

In our analysis the new owners are always national. The (domestic) total surplus and the privatized firm's profit are:

$$
V^{C N}=\frac{8-8 c+11 c^{2}}{18}-K_{g}-K_{p} ; \quad \Pi_{g}^{C N}=\left(\frac{1-2 c}{3}\right)^{2}
$$

\footnotetext{
${ }^{20}$ Superscript CN stands for Cournot-Nash equilibrium.
} 
In the case of full efficient privatization, recall that $c=0$.

In order to compare welfare before and after privatization, the price paid to the government for buying the firm matters. Since we are taking into account the shadow cost of public funds, it is not indifferent whether profits are public or private, and if the government is able to raise enough money from privatization. Given the equilibrium after privatization, the more money the government is able to raise by selling the public firm, the higher the welfare after the privatization. In the first instance, we give full bargaining power to the government; i.e., it is able to extract the whole profit from the privatized firm. In this case, total welfare in the Cournot-Nash equilibrium is:

$$
W^{C N}=\frac{1}{18}\left(2 \lambda+11 c^{2}+8-8 c(1+\lambda-c \lambda)\right)-(1+\lambda) K_{g}-K_{p}
$$

The following theorem states the result of the comparison when no efficiency gain occurs after privatization.

Theorem 9 Consider a mixed duopoly game in which the order of moves is endogenous. In addition, assume that by privatization the firm does not achieve any efficiency gain and all the profits are extracted by the government. Then, privatization always reduces welfare.

This result is in sharp contrast with those obtained assuming simultaneous playing. For example, de Fraja and Delbono (1989) show that assuming Cournot competition privatization may enhance welfare absent efficiency gains. ${ }^{21}$ The same result holds in the framework of the present paper. Disregarding the endogenous timing game, and comparing $W^{M N}$ from equation (9) and $W^{C N}$ from equation (12) $\forall(c, \lambda) \in A$, privatization may increase welfare. More precisely, it occurs when

$$
c>\frac{4 \lambda+6 \lambda^{2}+1}{26 \lambda+12 \lambda^{2}+8}
$$

Now, we move the analysis to the other extreme case: full efficient privatization. The following Theorem formalizes the result.

Theorem 10 Consider a mixed duopoly game in which the order of moves is endogenous. In addition, assume that by privatization the firm achieves full efficiency and all the profits are extracted by the government. Then, there exists a subset of the parameter $J \subset A$, such that the privatization reduces welfare.

In Figure 4 we graph the set $J$ in the parameters' space where a fully efficient privatization reduces welfare. Endogenizing the timing of competition, before and after privatization, enlarges this space with respect to the simultaneous case. In fact, it is easy to show that, assuming simultaneous competition, privatization reduces welfare if

$$
c<\frac{3(1+2 \lambda)^{2}-(1+3 \lambda) \sqrt{2(3+8 \lambda(1+\lambda))}}{3(1+\lambda)(3+8 \lambda)}
$$

\footnotetext{
${ }^{21}$ This result is obtained in a different setting with symmetric firms and increasing marginal costs.
} 


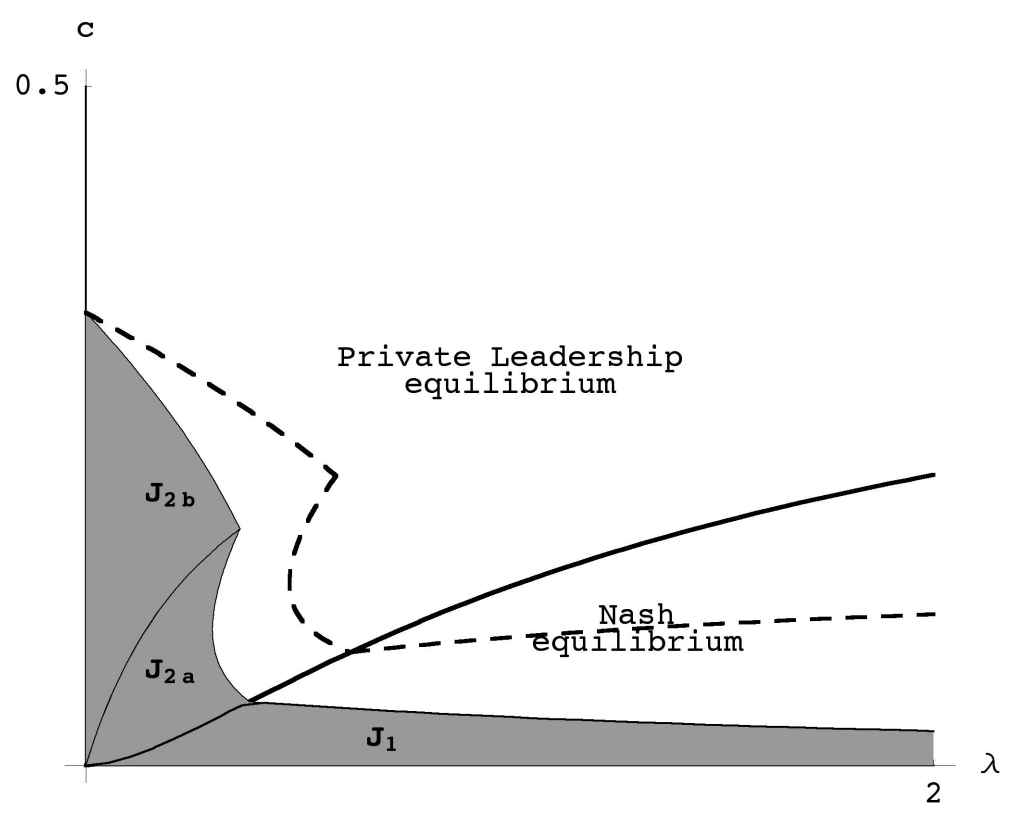

Figure 4: The welfare effect of a full efficient privatization: in gray the space of the parameters in $(c, \lambda)$ in which privatization reduces welfare when the government extracts all the profits from the privatized firm

It is interesting to notice that the level of $c$ such that public ownership is the dominant solution in terms of welfare is decreasing in $\lambda$. This occurs because, as $\lambda$ increases, the profit motivation has a larger weight in the public firm's decision. So, the allocative efficiency effect of the public ownership decreases and the productive efficiency effect of the privatization becomes more and more important. Thus, we can say that the more the public firm behaves as a profit maximizer, the better is to privatize it. This result is obtained assuming that the government is able to extract the whole profit from the new owners of the privatized firm. Suppose now that the government is able to take just half of the profit. How the previous result are affected? In Figure 4 we can see how the space of the parameters such that the privatization reduces welfare is enlarged. The dashed line delimits the space of a welfare-reducing full efficient privatization when the government sells the public firm at a price equal to half of the future profits.

An extreme result occurs when the firm is sold for free. In this latter case, a full efficient privatization always lowers welfare.

\section{Conclusions}

The aim of the present work is to characterize the equilibrium and analyze the effect of privatization in a mixed duopoly where an (inefficient) welfare-maximizing public firm competes in the quantities with a domestic private one.

We do not assume the timing of competition a priori. Rather, we endogenize the determination of simultaneous (Nash-Cournot) versus sequential (Stackelberg) games by applying 
the Hamilton and Slutsky (1990)'s model to this mixed duopoly framework.

Since we mainly refer to public utility markets open to competition, we assume that firms' production is characterized by increasing return to scale, with fixed cost and constant marginal cost. In this framework, we define the objective function of the public firm assuming that its management is instructed to maximize welfare taking into account the shadow cost of public funds. As the following citation suggests, this approach has been generally used to characterize public monopolies running a deficit.

$[\mathrm{M}]$ any public enterprises are natural monopolies, i.e. firms that exhibit increasing returns to scale. Once it has been proved desirable to run such an enterprise at all, its product should be priced at marginal cost provided the resulting deficit can be financed through lump-sum taxes. If there are not lump-sum, discrepancies between consumer and producer taxes will result in inefficiencies in the rest of the economy. (...) This has been taken as an argument for requiring the public enterprise to cover, by its own means, at least part of its deficit. (Marchand et al., 1984)

We believe that extending this approach to the mixed duopoly framework is rather natural and fills, at least partially, some gaps of the previous literature. Indeed, discussing the results of their paper, Beato and Mas-Colell (1984, p. 82) state:

Finally, the limitations of this paper and the need for further work should be clear. We have, for example, ruled out both fixed cost and the general equilibrium effects of distortions in other markets. We don't know if reasonable versions of the main results of this paper [...] are available in these richer settings.

The extensive process of privatization started in the eighties of the last century and still in place nowadays is essentially driven by the belief that private discipline and profit motivation can enhance efficiency. Moreover, privatization is also considered as a powerful instrument to raise money to reducing distortionary taxation. In this work we confute the general extent of these ideas. We show that, absent efficiency gains, privatization never increases welfare, and that an inefficient public firm may be preferred even when large efficiency gains could be realized by privatization. These result are obtained assuming that both private firm's profits and privatization proceeds are substitute for distortionary taxation. The distortionary model applied to the mixed oligopoly framework is not less important for our results. While after privatization only the simultaneous (Nash-Cournot) equilibrium can be implemented, with a public firm sequential outcomes - that are always welfare superior - may be sustained as SPE of the endogenous timing game. Therefore, privatization changes not only the ownership and the objective function of the public firm, but also the type of competition in the market.

Finally, the assumption of public firm inefficiency deserves a last comment.

From a theoretical point of view, the relationship between ownership and economic efficiency is still an open question. Theoretical support to privatization was provided by the 
theory of incentives that demonstrated how agency problems in state-owned enterprises can cause larger inefficiencies than in private-owned firms. In fact, profit maximizing owners subject to threats of bankruptcy and takeover have stronger incentives to reduce costs than politicians or bureaucrats. They would motivate and monitor appointed managers more efficiently than when there are wider and sometimes distorted objectives, soft budget constraints and complicated chains of command (World Bank, ed, 1995). In addition, Sappington and Stiglitz (1987) presents the "fundamental privatization theorem" providing conditions under which government production cannot improve upon private production. Nowadays, modern theory is less dogmatic in this respect (see Estrin and Pérotin, 1991). For example, an ownermanager would indeed have strong incentives to cut costs. But to privatize a managerial firm may increase costs, because the profit motive can reduce the incentive to pay for lower managerial slack (de Fraja, 1993; Willner, 2003). Public ownership may in some models mean excessive labour intensity and private ownership the opposite, with ambiguous consequences for overall productivity (see Pint, 1991). The ranking of ownership is sensitive to details in the objective function and reward schedule if low performance means that the manager is fired (Willner and Parker, 2007). Also, privatization often requires regulation, and hence an additional agency problem that may sometimes cost more than public ownership (Laffont and Tirole, 1991; Shapiro and Willig, 2001).

From an empirical point of view the picture is quite mixed. ${ }^{22}$ Most of the works report an increase in profitability after the privatization, but the evidence of productive efficiency improvements is less clear and the variance of the results is substantial (Cuervo and Villalonga, 2000).

\section{Appendix}

Proof of Lemma 4. Comparing the equilibrium profits $\Pi_{p}^{G L}$ in Table 2 with $\Pi_{p}^{M N}$ in equation (8), it easy to check that $\forall \lambda \geq 0$ :

(i) $\forall c \in\left(0, \frac{1+2 \lambda}{4(1+\lambda)}\right)$

$$
\Pi_{p}^{G L}-\Pi_{p}^{M N}>0 \quad \forall c>\bar{c}(\lambda)
$$

where

$$
\bar{c}(\lambda)=\frac{\lambda^{2}}{2 \lambda^{2}+3 \lambda+1} \quad \text { with } \frac{\partial \bar{c}(\lambda)}{\partial \lambda}>0
$$

(ii) $\forall c \in\left[\frac{1+2 \lambda}{4(1+\lambda)}, \frac{1}{2}\right), \Pi_{p}^{G L}-\Pi_{p}^{M N}>0$ always.

Thus, we define the subspace $F_{1}$ and $\widehat{F}_{1}$ as follows:

$$
F_{1}=\{(c, \lambda) \subseteq A \mid c>\bar{c}(\lambda)\} \quad \text { and } \quad \widehat{F}_{1}=\{(c, \lambda) \subseteq A \mid c \leq \bar{c}(\lambda)\}
$$

\footnotetext{
${ }^{22}$ See for example the reviews of Megginson and Netter (2001) and Willner (2001) that report the results of hundreds of empirical papers on privatization and on the comparison of private and public ownership.
} 
Proof of Lemma 5. Comparing the welfare level $W^{P L}$ in Table 3 with $W^{M N}$ in equation (9), it easy to check that $\forall \lambda \in(\bar{\lambda}):^{23}$

(i) $\forall c \in\left(0, \frac{\lambda}{3 \lambda+1}\right)$

$$
W^{P L}-W^{M N}>0 \quad \forall c>\underline{c}(\lambda)
$$

where

$$
\underline{c}(\lambda)=\frac{3 \lambda^{2}+7 \lambda^{3}}{21 \lambda+34 \lambda^{2}+17 \lambda^{3}+4} \quad \text { with } \frac{\partial \underline{c}(\lambda)}{\partial \lambda}>0
$$

(ii) $\forall c \in\left[\frac{\lambda}{3 \lambda+1}, \frac{1}{2}\right)$,

$$
W^{P L}-W^{M N}>0 \quad \forall \lambda \in(0, \bar{\lambda})
$$

Thus, we define the subspace $F_{2}$ and $\widehat{F}_{2}$ as follows:

$$
F_{2}=\{(c, \lambda) \subseteq A \mid c>\underline{c}(\lambda)\} \quad \text { and } \quad \widehat{F}_{2}=\{(c, \lambda) \subseteq A \mid c \leq \underline{c}(\lambda)\}
$$

\section{Proof of Theorem 6.}

a) When $(c, \lambda) \in \widehat{F}_{1}$ the private firm prefers the mixed duopoly Nash equilibrium to the public leadership equilibrium. When $(c, \lambda) \in \widehat{F}_{2}$ the public firm is better off in the Nash equilibrium than in the private leadership equilibrium. Therefore, in the intersection space $\widehat{F}_{1} \cap \widehat{F}_{2}$, no firm wants to be follower. Since $\forall \lambda \in(0, \bar{\lambda}), \underline{c}(\lambda)<\bar{c}(\lambda)$, it follows that $\widehat{F}_{2} \subset \widehat{F}_{1}$; then $\widehat{F}_{1} \cap \widehat{F}_{2}$ coincides with $\widehat{F}_{2}$. Given that each player always prefers to be the Stackelberg leader than a simultaneous player, point $i$ ) of Proposition 3 applies and the mixed duopoly Nash equilibrium is the unique SPE of the endogenous timing game.

b) When $(c, \lambda) \in \widehat{F}_{1}$ the private firm prefers the mixed duopoly Nash equilibrium to the public leadership equilibrium. When $(c, \lambda) \in F_{2}$ the public firm is better off in the private leadership equilibrium than in the mixed duopoly Nash equilibrium. So, point iii) of Proposition 3 applies and the Stackelberg equilibrium with the private firm acting as leader is the unique SPE of the endogenous timing game.

c) When $(c, \lambda) \in F_{1}$ the private firm prefers to play as Stackelberg follower than to play simultaneously. When $(c, \lambda) \in F_{2}$ the public firm prefers to play as Stackelberg follower than to play simultaneously. Since $\forall \lambda>0, \underline{c}(\lambda)<\bar{c}(\lambda)$, it follows that $F_{1} \subset F_{2}$; then $F_{1} \cap F_{2}$ coincides with $F_{1}$. So, point $\left.i i\right)$ of Proposition 3 applies and both Stackelberg equilibria belong to the set of the (pure strategy) SPE of the endogenous timing game.

\footnotetext{
${ }^{23}$ The threshold $\underline{c}<\frac{\lambda}{3 \lambda+1} \forall \lambda<5.37228$. Since $\lambda$ is a measure of the distortion by taxation, we are comfortable assuming that $\bar{\lambda}$ is lower than 5.37228. If $\lambda \geq 5.37228$ we would have that $W^{P L}<W^{M N}$ always.
} 
Proof of Theorem 7. In order to prove the result we need to consider three cases depending on the fact that boundary solutions may occur in the two sequential equilibria. By comparing the thresholds defined in Section 3.2, we have the following equilibria:

(i) when $(c, \lambda) \in F_{1}$ and $c<\frac{\lambda}{1+3 \lambda}$, both Stackelberg equilibria are interior. Then, the values of $W^{G L}, \Pi_{p}^{G L}, W^{P L}$ and $\Pi_{p}^{P L}$ of interest are those in the first row of Tables 2 and 3.

(ii) when $(c, \lambda) \in F_{1}$ and $\frac{\lambda}{1+3 \lambda}<c<\frac{1+2 \lambda}{4(1+\lambda)}$, the public firm does not produce in the private leadership equilibrium while it produces positive quantity in the public leadership equilibrium. Then, the values of $W^{G L}$ and $\Pi_{p}^{G L}$ of interest are are those in the first row of Table 2, while for $W^{P L}$ and $\Pi_{p}^{P L}$ we have to consider the values in the second row of Table 3.

(iii) when $(c, \lambda) \in F_{1}$ and $c>\frac{1+2 \lambda}{4(1+\lambda)}$, the public firm does not produce in both Stackelberg equilibria. Then, the values of $W^{G L}, \Pi_{p}^{G L}, W^{P L}$ and $\Pi_{p}^{P L}$ of interest are those in the second row of Tables 2 and 3.

Applying the criterion (10), straightforward but tedious computations show the result.

Proof of Theorem 9. In order to prove the result, we need to consider three cases: (i) Nash is the relevant equilibrium of the mixed duopoly; (ii) private leadership is the relevant equilibrium of the mixed duopoly with an interior solution;and (iii) private leadership with the public firm not producing is the relevant equilibrium of the mixed duopoly.

(i) By point a) in Theorem 6 Nash is the relevant equilibrium of the mixed duopoly game when $(c, \lambda) \in \widehat{F}_{2}$. So, we have to compare $W^{M N}$, defined in equation (9) with $W^{C N}$ (equation 12). Straightforward computations show that

$$
W^{M N}>W^{C N} \quad \forall(c, \lambda) \in \widehat{F}_{2}
$$

(ii) By points b) and c) in Theorem 6 and Theorem 7 the Stackelberg outcome with the private firm as leader is the relevant SPE of the mixed duopoly game when $(c, \lambda) \in F_{2}$. Moreover, when $c<\frac{\lambda}{3 \lambda+1}$ the public firm produces positive quantity in the equilibrium. Then, we have to compare the value of $W^{P L}$ in the first row of Table 3 with $W^{C N}$ (equation 12). Straightforward computations show that

$$
W^{P L}>W^{C N} \quad \forall(c, \lambda) \in F_{2}, \quad c<\frac{\lambda}{3 \lambda+1}
$$

(iii) When $c \geq \frac{\lambda}{3 \lambda+1}$, the public firm does not produce in the private leadership equilibrium. Thus, we have to compare the value of $W^{P L}$ in the second row of Table 3 with $W^{C N}$ (equation 12). Straightforward computations show that

$$
W^{P L}>W^{C N} \quad \forall(c, \lambda) \in F_{2}, \quad c>\frac{\lambda}{3 \lambda+1}
$$


Proof of Theorem 10. When the privatized firm achieves full efficiency gains, welfare after privatization is:

$$
\left.W^{C N}\right|_{c=0}=\frac{4+\lambda}{9}-(1+\lambda) K_{g}-K_{p}
$$

In order to prove the result we have to distinguish between three cases as in Theorem 9 .

(i) By point a) in Theorem 6 Nash is the relevant equilibrium of the mixed duopoly game when $(c, \lambda) \in \widehat{F}_{2}$. So, we have to compare $W^{M N}$, defined in equation (9) with $W^{C N}$ (equation 15). Straightforward computations show that

$$
W^{M N} \geq\left. W^{C N}\right|_{c=0} \quad \forall(c, \lambda) \in \widehat{F}_{2}, \quad c<\frac{3(1+2 \lambda)^{2}-(1+3 \lambda) \sqrt{2(3+8 \lambda(1+\lambda))}}{3(1+\lambda)(3+8 \lambda)}
$$

Thus, we can define the subset

$$
J_{1}=\left\{(c, \lambda) \in \widehat{F}_{2} \mid c<\frac{3(1+2 \lambda)^{2}-(1+3 \lambda) \sqrt{2(3+8 \lambda(1+\lambda))}}{3(1+\lambda)(3+8 \lambda)}\right\}
$$

Referring to the definition of the subset $\widehat{F}_{2}$ in (14), it is easy to check that $J^{1}$ is a nonempty set.

(ii) By points b) and c) in Theorem 6 and Theorem 7 the private leadership equilibrium is the relevant SPE of the mixed duopoly game when $(c, \lambda) \in F_{2}$. Moreover, when $c<\frac{\lambda}{3 \lambda+1}$ the public firm produces positive quantity in the equilibrium. Then, we have to compare the value of $W^{P L}$ in the first row of Table 3 with $W^{C N}$ (equation 15). First of all, define

$$
F_{2 a}=\left\{(c, \lambda) \in F_{2} \mid c<\frac{\lambda}{3 \lambda+1}\right\}
$$

Straightforward computations show that:

$$
\begin{aligned}
W^{P L} & \geq\left. W^{C N}\right|_{c=0} \\
\forall(c, \lambda) & \in F_{2 a}, \quad 9 c^{2}(1+\lambda)^{2}(4+9 \lambda)-18 c \lambda(1+\lambda)(2+3 \lambda)+4 \lambda-7 \lambda^{3}>0
\end{aligned}
$$

Thus we can define the subset

$$
J_{2 a}=\left\{(c, \lambda) \in F_{2 a} \mid 9 c^{2}(1+\lambda)^{2}(4+9 \lambda)-18 c \lambda(1+\lambda)(2+3 \lambda)+4 \lambda-7 \lambda^{3}>0\right\}
$$

that is nonempty.

(iii) Defining

$$
F_{2 b}=\left\{(c, \lambda) \in F_{2} \mid c \geq \frac{\lambda}{3 \lambda+1}\right\}
$$

the public firm does not produce in the private leadership equilibrium. Then, we have to compare the value of $W^{P L}$ in the second row of Table 3 with $W^{C N}$ (equation 15). Straightforward computations show that the subset $J^{2 b} \subset F_{2 b}$ such that privatization reduces welfare is not empty.

$$
J_{2 b}=\left\{(c, \lambda) \in F_{2 b} \mid c<\frac{1}{3} \sqrt{1-2 \lambda} \Leftrightarrow W^{\operatorname{Pr} L}-W^{F E} \geq 0\right\}
$$


Then, the subset of parameters' values such that a full efficient privatization with full bargaining power to the government reduces welfare is the following:

$$
J=J_{1} \cup J_{2 a} \cup J_{2 b}
$$

\section{References}

Amir, Rabah and Anna Stepanova, "Second-mover advantage and price leadership in Bertrand duopoly," Games and Economic Behavior, April 2006, 55 (1), 1-20.

- and Isabel Grilo, "Stackelberg versus Cournot Equilibrium," Games and Economic Behavior, January 1999, 26 (1), 1-21.

Beato, Paulina and Andreu Mas-Colell, "The Marginal Cost Pricing Rule as a Regulation Mechanism in Mixed Markets," in Maurice Marchand, Pierre Pestieu, and Henry Tulkens, eds., The Performance of Public Enterprises, Vol. 33 of Studies in Mathematical and Managerial Economics, Amsterdam, NL: Elsevier Science B.V., January 1984, pp. 81100.

Bös, Dieter, Public Enterprise Economics: Theory and Applications, 2nd ed., Vol. 23 of Advanced Textbooks in Economics, Amsterdam, NL: North Holland, January 1986.

Cooper, Russell W., Douglas V. DeJong, Robert Forsthe, and Thomas W. Ross, "Selection criteria in coordination games: Some experimental results," American Economic Review, March 1990, 80 (1), 218-233.

Cornes, Richard C. and Mehrdad Sepahvand, "Cournot Vs Stackelberg Equilibria with a Public Enterprise and International Competition," Working Paper Series, SSRN, July 2003.

Cremer, Helmuth, Maurice Marchand, and Jacques-François Thisse, "The Public Firm as an Instrument for Regulating an Oligopolistic Market," Oxford Economic Papers, April 1989, 41 (2), 283-301.

Cuervo, Alvaro and Belen Villalonga, "Explaining the Variance in the Performance Effects of Privatization," Academy of Management Review, July 2000, 25 (3), 581-590.

de Fraja, Giovanni, "Productive efficiency in public and private firms," Journal of Public Economics, January 1993, 50 (1), 15-30.

- and Flavio Delbono, "Alternative Strategies of a Public Enterprise in Oligopoly," Oxford Economic Papers, April 1989, 41 (2), 302-311. 
_ and _, "Game Theoretic Models of Mixed Oligopoly," Journal of Economic Surveys, March 1990, \& (1), 1-17.

Ellison, Glenn, "Learning, Local Interaction, and Coordination," Econometrica, September 1993, 61 (5), 1047-1071.

Estrin, Saul and Virginie Pérotin, "Does ownership always matter?," International Journal of Industrial Organization, March 1991, 9 (1), 55-72.

Fjell, Kenneth and Debashis Pal, "A mixed oligopoly in the presence of foreign private firms," Canadian Journal of Economics, August 1996, 29 (3), 737-743.

Hamilton, Jonathan H. and Steven M. Slutsky, "Endogenous timing in duopoly games: Stackelberg or cournot equilibria," Games and Economic Behavior, March 1990, 2 (1), 29 46.

Harsanyi, John C. and Reinhard Selten, A General Theory of Equilibrium Selection in Games, Cambridge, MA: The MIT Press, June 1988.

Hindriks, Jean and Denis Claude, "Strategic Privatization and Regulation Policy in Mixed Markets," The Icfai Journal of Managerial Economics, February 2006, 2 (4), 7-26.

Kandori, Michihiro, George J. Mailath, and Rafael Rob, "Learning, Mutation, and Long Run Equilibria in Games," Econometrica, January 1993, 61 (1), 29-56.

Laffont, Jean-Jacques and Jean Tirole, "Using Cost Observation to Regulate Firms," Journal of Political Economy, June 1986, 94 (3), 614-641.

_ and _, "Privatization and Incentives," Journal of Law, Economics, ES Organization, January 1991, 7, 84-105.

_ and _ , A Theory of Incentives in Procurement and Regulation, Cambridge, MA: The MIT Press, March 1993.

Marchand, Maurice, Pierre Pestieu, and Henry Tulkens, "The Performance of Public Enterprises: Normative, Positive and Empirical Issues," in Maurice Marchand, Pierre Pestieu, and Henry Tulkens, eds., The Performance of Public Enterprises, Vol. 33 of Studies in Mathematical and Managerial Economics, Amsterdam, NL: Elsevier Science B.V., January 1984, pp. 3-42.

Martin, Steven, "Globalization and the Natural Limits of Competition," in Manfred Neumann and Jürgen Weigand, eds., The International Handbook of Competition, Cheltenham, UK: Edward Elgar, February 2004, pp. 16-64.

Matsumura, Toshihiro, "Partial privatization in mixed duopoly," Journal of Public Economics, December 1998, 70 (3), 473-483. 
_ , "Stackelberg Mixed Duopoly with a Foreign Competitor," Bulletin of Economic Research, July 2003, 55 (3), 275-287.

Meade, James E., "Price and Output Policy of State Enterprise," The Economic Journal, December 1944, 54 (215/216), 321-339.

Megginson, William L. and Jeffry M. Netter, "From State to Market: A Survey of Empirical Studies on Privatization," Journal of Economic Literature, June 2001, 39 (2), $321-389$.

Pal, Debashis, "Endogenous timing in a mixed oligopoly," Economics Letters, November 1998, 61 (2), 181-185.

- and Mark D. White, "Mixed Oligopoly, Privatization, and Strategic Trade Policy," Southern Economic Journal, October 1998, 65 (2), 264-281.

Pint, Ellen M., "Nationalization vs. regulation of monopolies : The effects of ownership on efficiency," Journal of Public Economics, March 1991, 44 (2), 131-164.

Rees, Ray, Public Enterprise Economics, 2nd ed., London, UK: Palgrave Macmillan, December 1984.

Sappington, David E. M. and Joseph E. Stiglitz, "Privatization, Information and Incentives," Journal of Policy Analysis and Management, Summer 1987, 6 (4), 567-582.

Sepahvand, Mehrdad, "Public Enterprise Strategies in a Market Open to Domestic and International Competition," Annales d'Économie et de Statistique, July 2004, 75-76, 135153.

Shapiro, Carl and Robert D. Willig, "Economic Rationales for the Scope of Privatization," in David Parker, ed., Privatisation and Corporate Performance, Vol. 123 of The International Library of Critical Writings in Economics, Cheltenham, UK: Edward Elgar, February 2001, pp. 39-71.

Stehmann, Oliver and Rob Borthwick, "Infrastructure competition and the European Union's telecommunications policy," Telecommunications Policy, November 1994, 18 (8), 601-615.

Taschdjian, Martin, "Alternative Models of Telecommunications Policy: Services Competition versus Infrastructure Competition," in "Twenty-Fifth Annual Telecommunications Policy Research Conference" Alexandria, VA September 1997.

van Damme, Eric and Sjaak Hurkens, "Endogenous price leadership," Games and Economic Behavior, May 2004, 47 (2), 404-420. 
Van Huyck, John B., Raymond C. Battalio, and Richard O. Beil, "Tacit coordination games, strategic uncertainty, and coordination failure," American Economic Review, March 1990, 80 (1), 234-248.

Willner, Johan, "Ownership, efficiency, and political interference," European Journal of Political Economy, November 2001, 17 (4), 723-748.

_ , "Privatization - A Sceptical Analysis," in David Parker and David S. Saal, eds., International Handbook of Privatization, Cheltenham, UK: Edward Elgar, May 2003, chapter 4, pp. $60-86$.

- and David Parker, "The Performance of Public and Private Enterprise under Conditions of Active and Passive Ownership and Competition and Monopoly," Journal of Economics, April 2007, 90 (3), 221-253.

World Bank, ed., Bureaucrats in Business: The Economics and Politics of Government Ownership, World Bank Policy Research Report, New York, NJ: Oxford University Press, June 1995. 


\section{Recent titles \\ CORE Discussion Papers}

2007/75. Jacques H. DREZE and P. Jean-Jacques HERINGS. Kinky perceived demand curves and Keynes-Negishi equilibria.

2007/76. Yu. NESTEROV. Gradient methods for minimizing composite objective function.

2007/77. Giacomo VALLETTA. A fair solution to the compensation problem.

2007/78. Claude D'ASPREMONT, Rodolphe DOS SANTOS FERREIRA and Jacques THEPOT. Hawks and doves in segmented markets: a formal approach to competitive aggressiveness.

2007/79. Claude D'ASPREMONT, Rodolphe DOS SANTOS FERREIRA and Louis-André GERARDVARET. Imperfect competition and the trade cycle: guidelines from the late thirties.

2007/80. Andrea SILVESTRINI. Testing fiscal sustainability in Poland: a Bayesian analysis of cointegration.

2007/81. Jean-François MAYSTADT. Does inequality make us rebel? A renewed theoretical model applied to South Mexico.

2007/82. Jacques H. DREZE, Oussama LACHIRI and Enrico MINELLI. Shareholder-efficient production plans in a multi-period economy.

2007/83. Jan JOHANNES, Sébastien VAN BELLEGEM and Anne VANHEMS. A unified approach to solve ill-posed inverse problems in econometrics.

2007/84. Pablo AMOROS and M. Socorro PUY. Dialogue or issue divergence in the political campaign?

2007/85. Jean-Pierre FLORENS, Jan JOHANNES and Sébastien VAN BELLEGEM. Identification and estimation by penalization in nonparametric instrumental regression.

2007/86. Louis EECKHOUDT, Johanna ETNER and Fred SCHROYEN. A benchmark value for relative prudence.

2007/87. Ayse AKBALIK and Yves POCHET. Valid inequalities for the single-item capacitated lot sizing problem with step-wise costs.

2007/88. David CRAINICH and Louis EECKHOUDT. On the intensity of downside risk aversion.

2007/89. Alberto MARTIN and Wouter VERGOTE. On the role of retaliation in trade agreements.

2007/90. Marc FLEURBAEY and Erik SCHOKKAERT. Unfair inequalities in health and health care.

2007/91. Frédéric BABONNEAU and Jean-Philippe VIAL. A partitioning algorithm for the network loading problem.

2007/92. Luc BAUWENS, Giordano MION and Jacques-François THISSE. The resistible decline of European science.

2007/93. Gaetano BLOISE and Filippo L. CALCIANO. A characterization of inefficiency in stochastic overlapping generations economies.

2007/94. Pierre DEHEZ. Shapley compensation scheme.

2007/95. Helmuth CREMER, Pierre PESTIEAU and Maria RACIONERO. Unequal wages for equal utilities.

2007/96. Helmuth CREMER, Jean-Marie LOZACHMEUR and Pierre PESTIEAU. Collective annuities and redistribution.

2007/97. Mohammed BOUADDI and Jeroen V.K. ROMBOUTS. Mixed exponential power asymmetric conditional heteroskedasticity.

2008/1. Giorgia OGGIONI and Yves SMEERS. Evaluating the impact of average cost based contracts on the industrial sector in the European emission trading scheme.

2008/2. Oscar AMERIGHI and Giuseppe DE FEO. Privatization and policy competition for FDI.

2008/3. Wlodzimierz SZWARC. On cycling in the simplex method of the Transportation Problem.

2008/4. John-John D'ARGENSIO and Frédéric LAURIN. The real estate risk premium: A developed/emerging country panel data analysis.

2008/5. Giuseppe DE FEO. Efficiency gains and mergers.

2008/6. Gabriella MURATORE. Equilibria in markets with non-convexities and a solution to the missing money phenomenon in energy markets.

2008/7. Andreas EHRENMANN and Yves SMEERS. Energy only, capacity market and security of supply. A stochastic equilibrium analysis. 


\section{Recent titles}

\section{CORE Discussion Papers - continued}

2008/8. Géraldine STRACK and Yves POCHET. An integrated model for warehouse and inventory planning.

2008/9. Yves SMEERS. Gas models and three difficult objectives.

2008/10. Pierre DEHEZ and Daniela TELLONE. Data games. Sharing public goods with exclusion.

2008/11. Pierre PESTIEAU and Uri POSSEN. Prodigality and myopia. Two rationales for social security.

2008/12. Tim COELLI, Mathieu LEFEBVRE and Pierre PESTIEAU. Social protection performance in the European Union: comparison and convergence.

2008/13. Loran CHOLLETE, Andréas HEINEN and Alfonso VALDESOGO. Modeling international financial returns with a multivariate regime switching copula.

2008/14. Filomena GARCIA and Cecilia VERGARI. Compatibility choice in vertically differentiated technologies.

2008/15. Juan D. MORENO-TERNERO. Interdependent preferences in the design of equal-opportunity policies.

2008/16. Ana MAULEON, Vincent VANNETELBOSCH and Wouter VERGOTE. Von NeumannMorgenstern farsightedly stable sets in two-sided matching.

2008/17. Tanguy ISAAC. Information revelation in markets with pairwise meetings: complete information revelation in dynamic analysis.

2008/18. Juan D. MORENO-TERNERO and John E. ROEMER. Axiomatic resource allocation for heterogeneous agents.

2008/19. Carlo CAPUANO and Giuseppe DE FEO. Mixed duopoly, privatization and the shadow cost of public funds.

\section{Books}

Y. POCHET and L. WOLSEY (eds.) (2006), Production planning by mixed integer programming. New York, Springer-Verlag.

P. PESTIEAU (ed.) (2006), The welfare state in the European Union: economic and social perspectives. Oxford, Oxford University Press.

H. TULKENS (ed.) (2006), Public goods, environmental externalities and fiscal competition. New York, Springer-Verlag.

V. GINSBURGH and D. THROSBY (eds.) (2006), Handbook of the economics of art and culture. Amsterdam, Elsevier.

J. GABSZEWICZ (ed.) (2006), La différenciation des produits. Paris, La découverte.

L. BAUWENS, W. POHLMEIER and D. VEREDAS (eds.) (2008), High frequency financial econometrics: recent developments. Heidelberg, Physica-Verlag.

P. VAN HENTENRYCKE and L. WOLSEY (eds.) (2007), Integration of AI and OR techniques in constraint programming for combinatorial optimization problems. Berlin, Springer.

\section{CORE Lecture Series}

C. GOURIÉROUX and A. MONFORT (1995), Simulation Based Econometric Methods.

A. RUBINSTEIN (1996), Lectures on Modeling Bounded Rationality.

J. RENEGAR (1999), A Mathematical View of Interior-Point Methods in Convex Optimization.

B.D. BERNHEIM and M.D. WHINSTON (1999), Anticompetitive Exclusion and Foreclosure Through Vertical Agreements.

D. BIENSTOCK (2001), Potential function methods for approximately solving linear programming problems: theory and practice.

R. AMIR (2002), Supermodularity and complementarity in economics.

R. WEISMANTEL (2006), Lectures on mixed nonlinear programming. 
Département des Sciences Économiques de l'Université catholique de Louvain

Institut de Recherches Économiques et Sociales

Place Montesquieu, 3

1348 Louvain-la-Neuve, Belgique 